\title{
ENDOSCOPY AUDIT IN THE ENT OUTPATIENT CLINIC OF THE LAGOS STATE UNIVERSITY TEACHING HOSPITAL
}

\author{
S.T Yahaya ${ }^{1}$, E.N Jebbin ${ }^{1}$, V.A Adekoya ${ }^{1}$, A.P Adeyinka ${ }^{1}$, O.Olubi ${ }^{1}$, A.A \\ Adesanya $^{1}$, F.O Nwachukwu ${ }^{1}$, O.A Fasina ${ }^{1}$. \\ dreyintejebbin89@gmail.com \\ ${ }^{1}$ Department of Otorhinolaryngology, Lagos State University Teaching Hospital, Lagos, \\ Nigeria. \\ Post code: 100271.
}

\begin{abstract}
Background:

Endoscopy is a minimally invasive diagnostic tool useful in medical practice and also in the field of Otorhinolaryngology to visualize the interior surfaces of a tissue or organ that are not usually seen when performing a standard examination of the larynx and surrounding structures. This serves both a diagnostic and therapeutic purpose.
\end{abstract}

Aims and Objectives:

(1) To ascertain the number of video laryngoscopy and nasal endoscopy carried out in the ORL Outpatient Clinic of the Lagos State University Teaching Hospital.

(2) To identify the common diagnosis made after both procedures.

Patients and Method:

This was a 1 year retrospective study (March 2020 to March 2021) at the ENT Outpatient Clinic of the Lagos State University Teaching Hospital, Ikeja, Lagos, Nigeria. 219 patients had either a nasal endoscopy or video laryngoscopy within the study period. Data collected included the bio data, symptoms, procedure done and diagnosis post procedure. Data was analyzed using SPSS version 20.

Result:

219 patients underwent endoscopy in the ENT Outpatient Clinic of the Lagos State University Teaching Hospital within the study duration. The study population was made up of 73 males and 146 females with a Male: female ratio of 1:2. Age range was 11 to 80 years. 143 patients had Video laryngoscopy, 73 had Nasal endoscopy and 3 patients had both procedures.

The commonest symptoms for patients that had nasal endoscopy were nasal blockage and nasal discharge with a frequency of $31.58 \%$ and $28.95 \%$ respectively while Chronic rhinosinusitis, Nasal polyposis and Nasopharyngeal tumor were the common diagnosis made with a percentage of $43.8 \%, 15.73 \%$ and $13.48 \%$ respectively.

Pre-operative assessment of patients for thyroidectomy was the commonest indication for 
video laryngoscopy (35.29\%) followed by hoarseness/voice change (24.51\%). Vocal cord paralysis (28.97\%), chronic pharyngitis (19.63\%) and chronic laryngitis $(11.21 \%)$ were the common diagnosis made after the procedure.

\section{Conclusion:}

Nasal endoscopy and Video laryngoscopy remains an essential diagnostic tool in ORL practice and its use cannot be over emphasized.

Keywords: Type your keywords here, separated by semicolons ; ORL- Otorhinolaryngology; ENTEar, Nose and throat; Video-laryngoscopy; Nasal endoscopy; Chronic rhinosinusitis; Nasal polyposis; Nasopharyngeal tumor. 


\section{Main text}

\section{INTRODUCTION}

3. Endoscopy is a minimally invasive diagnostic tool useful in medical practice and also in the field of Otorhinolaryngology. It is used to visualize the interior surfaces of a tissue or organ that are not usually seen while performing a standard examination. It is recommended as a first line diagnostic tool in nasal diagnosis like rhinosinusitis in the practice of ORL.

4. Laryngoscopy is a medical procedure used in visualizing the base of the tongue and larynx. Direct laryngoscopy can be done using a rigid or flexible endoscope. It is effective for diagnosis of laryngeal pathologies, throat pain and difficulty in swallowing. It is an important diagnostic tool for the ENT Surgeon. It is also important in evaluating patients at risk of laryngeal cancer.

5. The procedure aids an expert in the visualization of the vocal cord and its surrounding structures. Likewise, biopsies of tissues can be done as well as removal of polyps and other suspicious tissues that may exist on the larynx and its surrounding structures.

6. There were few reports in the literature about its use in ORL practice in Nigeria thus necessitating our aim for this study. This study is to show the number of patients who visited the ENT Outpatient Clinic of the Lagos State University Teaching hospital with symptoms and signs that required endoscopic examination either nasal endoscopy, video laryngoscopy or both.

\section{MATERIALS AND METHODS}

8. This is a retrospective study carried out in the Outpatient Clinic of the ENT Department of the Lagos State University Teaching Hospital between March 2020 and March 2021.

9. 219 patients during this study period had either nasal endoscopy or video laryngoscopy.

10. Nasal endoscopy was done using Hopkins rod endoscope of $0^{0}$ (diameter $4 \mathrm{~mm}$, length $18 \mathrm{~cm}$ ) by standard three pass technique.

11. Video laryngoscopy was also carried out.

12. Data collected were bio data, symptoms of patients, indications, procedure done, findings and diagnosis post procedure.

13. Data were entered into SPSS version 20 and analyzed.

\section{RESULT}


15. 219 patients underwent endoscopy in the ENT Outpatient Clinic of the Lagos State University Teaching Hospital from March 2020 to March 2021. The study population was made up of 73 males and 146 females. 143 patients had Video laryngoscopy, 73 had Nasal endoscopy and 3 patients had both procedures.

16. Common symptoms in patients who had a nasal endoscopy were nasal blockage (31.58\%), nasal discharge (28.95\%) and recurrent sneezing (19.74\%). Chronic rhinosinusitis, Nasal polyposis and Nasopharyngeal tumor were the most common diagnosis made.

17. Pre-operative assessment of patients for thyroidectomy, hoarseness/voice change, throat itching/irritation were the common indications for the video laryngoscopy.

18. Vocal cord paralysis (28.97\%), chronic pharyngitis (19.63\%) and chronic laryngitis $(11.21 \%)$ were the common diagnosis made after the procedure.

Figure 1

Pie Chart showing the proportion of procedures done

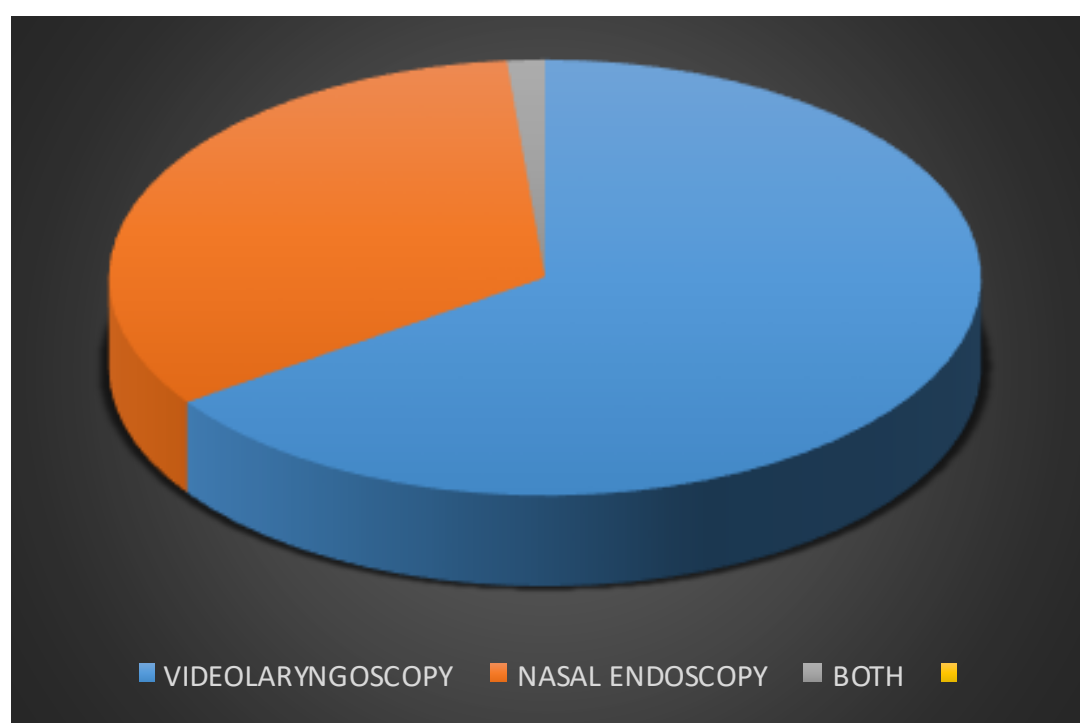

Video laryngoscopy: $65.29 \%$

Nasal Endoscopy:

$33.33 \%$

Both: $1.37 \%$ 
Figure 2:

Table showing the Age range of patients

\begin{tabular}{|l|l|l|}
\hline Age(years) & Frequency & Percentage \\
\hline $11-20$ & 13 & $5.93 \%$ \\
\hline $21-30$ & 29 & $13.24 \%$ \\
\hline $31-40$ & 44 & $20.09 \%$ \\
\hline $41-50$ & 59 & $26.94 \%$ \\
\hline $51-60$ & 37 & $16.89 \%$ \\
\hline $61-70$ & 26 & $11.87 \%$ \\
\hline $71-80$ & 11 & $5.02 \%$ \\
\hline Total & 219 & $100 \%$ \\
\hline
\end{tabular}

Figure 3:

Table showing symptoms of patients that had Nasal Endoscopy

\begin{tabular}{|l|l|l|}
\hline Symptoms & Frequency & Percentage \\
\hline Nasal discharge & 22 & $28.95 \%$ \\
\hline Nasal blockage & 24 & $31.58 \%$ \\
\hline Recurrent sneezing & 15 & $19.74 \%$ \\
\hline Snoring & 9 & $11.84 \%$ \\
\hline Post nasal drip & 6 & $7.89 \%$ \\
\hline
\end{tabular}

Figure 4:

Table showing diagnosis post Nasal endoscopy

\begin{tabular}{|l|l|l|}
\hline Diagnosis & Frequency & Percentage\% \\
\hline Chronic Rhino sinusitis & 39 & 43.8 \\
\hline Allergic Rhino sinusitis & 10 & 11.2 \\
\hline Sino-nasal tumor & 5 & 5.62 \\
\hline Nasal polyposis & 14 & 15.73 \\
\hline Nasopharyngeal tumor & 12 & 13.48 \\
\hline Septal spur & 2 & 2.25 \\
\hline Normal findings & 7 & 7.87 \\
\hline Total & 89 & $100 \%$ \\
\hline
\end{tabular}


Figure 5:

Table showing indications for Video laryngoscopy

\begin{tabular}{|l|l|l|}
\hline Indication/Symptoms & Frequency & Percentage\% \\
\hline Hoarseness/voice change & 25 & 24.51 \\
\hline $\begin{array}{l}\text { Pre-operative assessment for } \\
\text { thyroidectomy }\end{array}$ & 36 & 35.29 \\
\hline Feed regurgitation & 4 & 3.92 \\
\hline Throat discomfort/irritation & 20 & 19.61 \\
\hline $\begin{array}{l}\text { Post-operative assessment } \\
\text { following thyroidectomy }\end{array}$ & 5 & 4.90 \\
\hline Difficult decannulation & 3 & 2.94 \\
\hline Throat pain & 5 & 4.90 \\
\hline $\begin{array}{l}\text { Foreign body sensation in } \\
\text { throat }\end{array}$ & 4 & 3.92 \\
\hline Total & 102 & 100 \\
\hline
\end{tabular}

Figure 6:

Table showing diagnosis post Video laryngoscopy

\begin{tabular}{|l|l|l|}
\hline Diagnosis & Frequency & Percentage\% \\
\hline Chronic Pharyngitis & 21 & 19.63 \\
\hline Vocal cord paralysis & 31 & 28.97 \\
\hline $\begin{array}{l}\text { Laryngo pharyngeal reflux } \\
\text { disease }\end{array}$ & 4 & 3.74 \\
\hline Chronic laryngitis & 12 & 11.21 \\
\hline Laryngeal papillomatosis & 2 & 1.87 \\
\hline Globus Pharyngeus & 1 & 0.93 \\
\hline Normal finding & 36 & 33.64 \\
\hline Total & 107 & 100 \\
\hline
\end{tabular}

\section{DISCUSSION}

The usefulness of Laryngoscopy as an important tool in the visualization of the larynx and pharynx during the examination of the head and neck cannot be over emphasized. The commonest indication for video-laryngoscopy in our centre happened to be pre-operative assessment of patients being worked up for thyroidectomy (36\%) to visualize the vocal 
cords, followed by hoarseness/voice change at $25 \%$ and this was also the case in a study by ${ }^{3}$ Onotai et.al in Port Harcourt where the commonest indication was also pre-operative assessment for thyroidectomy (28.7\%) followed by Globus Pharyngeus and hoarseness at $21 \%$ and $17.3 \%$ respectively. Another study by ${ }^{5}$ Olaosun et.al had similar findings as seen in our study.

In a study by ${ }^{6}$ Adoga et.al, Laryngoscopy was the commonest endoscopic procedure which was also in tandem with our study where $65.3 \%$ of patients had a Video Laryngoscopy. In our study, $33.64 \%$ of the patients had normal video-Laryngoscopic findings which was also similar with the study in Port-Harcourt ${ }^{3}$.

The commonest symptom for patients that had nasal endoscopy according to ${ }^{7}$ Y.K Maru et.al was nasal obstruction ( $89 \%$ ) which was also the case in our study. According to Samuel et.al, Nasal obstruction and discharge were the most common symptoms which was the same in our study.

Nasal endoscopy is an important tool in making diagnosis of nasal polyps. This was the case in our study where a diagnosis of nasal polyps was seen in $15.73 \%$ of patients.

Chronic rhino sinusitis and nasal polyposis were the major diagnosis made post nasalendoscopy according to ${ }^{9}$ Batra and this was similar in our study where $43.8 \%$ and $15.74 \%$ of patients had chronic rhino sinusitis and nasal polyps respectively.

First, second and third passes were done in other to visualize the inferior nasal meatus, middle nasal meatus, middle turbinate, anterior wall of the sphenoid, spheno ethmoidal recess and the superior nasal meatus ${ }^{10}$. These steps were followed while carrying out nasal endoscopy in our centre.

\section{REFERENCES}

1. Chuck Leider. What is a Nasal Endoscopy procedure? (Indications, side effect and uses)Feb 27, 2018.

2. Gilead Berger, David M Steinberg, Aron Popovtzer, Dov Ophir. Endoscopy versus radiography for the diagnosis of acute bacterial rhinosinusitis. Eur Arch Otorhinolaryngol.

3. Lucky Obukowho Onotai, Chibuike Nwosu. Laryngoscopy: Appraisal of 202 procedures carried out in two centres in Port Harcourt, Nigeria. The Nigerian Health journal. ISSN 1597-4292.

4. Holsinger FC, Kies MS, Weinstock YE, Lewin JS, Hajibashi S, Nolen DD, Weber R., Laccourreye O. Examination of the larynx and pharynx. NEngl J Med. 2008; 358:e2. 7 
5. Olaosun AO, Oguntola AS, Adegbosin O, Akinloye A. Mirror laryngoscopy: a review of 43 cases. Surg J. 2009; 4(2): 29-34.

6. A S Adoga, AA Otene, OG Nwaorgu. An audit of endoscopic otorhinolarngological practice in Jos, Nigeria. High Land Medical Research Journal. Vol 14. No.1(2014).

7. Y.K Maru, Y. Gupta. Nasal endoscopy versus other diagnostic tools in Sino-nasal disease. Indian J Otolaryngol Head Neck Surg. 2016 Jun; 68(2): 202-206.

8. Samuel Oluyomi Ayodele, Olushola Abdulrahman Afolabi, Segun Segun-Busari, Habeeb Kayodele Omokanye, Foluwasayo Emmanuel Ologe. Clinical evaluation and nasoendoscopic scores of patients with chronic rhinosinusitis in Ilorin, Nigeria. Pan Afr Med J. 2021; 38: 396.

9. Batra PS. The role of endoscopy in the allergist's office. Curr Allergy Asthma Rep. 2006 May;6(3):228-31. [PubMed] [Google Scholar]

10. Beule AG. Physiology and pathophysiology of respiratory mucosa of the nose and the paranasal sinuses. GMS Curr Top Otorhinolaryngol Head Neck Surg. 2010;9:Doc07 (PMC Free article) (Pubmed). 